\title{
Biogeology. Biosphere from the Archean to Technogene
}

\author{
Rudko G. \\ State Commission of Ukraine on Mineral Resources 18/7 of 816, Kutuzov Street, Kiev 01133, Ukraine
}

\begin{abstract}
Biogeological history of the Earth was considered as a process of continuous transformation and permanent adaptation from original forms of life to its current state. The development of life on Earth arose under the conditions of changes in geological processes, chemical composition of the atmosphere and the aquatic environment during the periods between global catastrophes. As a result, more than 3.8 billion years were needed to form anthropogenic system "man—geological and adjacent environment", which transformed the biosphere according to human needs, creating a precedent of inconsistency between human needs and biosphere resources. The main scenarios of human and biosphere development were determined in the result of technogene. Scenarios of technogene progress and human role under conditions of intense transformation of the biosphere due to anthropogenic activities were investigated as well.
\end{abstract}

Key words: Biosphere, biota, geodynamics, geological environment, environmental safety, environmental disaster, stratigraphic unit.

\section{Introduction}

Today humanity has found themselves in the situation where the contradictions between the needs and available resources of the biosphere reached a critical point. Based on the results of recent research new approaches to exit from these conditions required. The author considered the modern theory of the origin and development of life, the formation of the atmosphere and the water balance of our planet.

\section{Main Body Material}

The oldest known minerals have the age of 4.2 billion years, and the age of the oldest rocks in which was found organic carbon is about 3.8 billion years. The first probable traces of life appeared on the Earth simultaneously with the first probable water traces [1].

Until quite recently it was believed that the origin of life on the Earth was preceded by prolonged (billions years) chemical evolution that included spontaneous synthesis and organic molecules polymerization, its conglutination into complex systems-precursors of cells, evolution formation of metabolism etc. The main hypothesis of the origin of life on the Earth was

Corresponding author: Professor Georgii Illich Rudko, Dr., Sci. (Geol.-Mineral.), Dr. Sci. (Geograph.), Dr. Sci. (Tech.), research fields: geology, medical geology, geoecology, etc. abiogenesis hypothesis: the first biological systems were formed by inorganic matter, the first cells appeared (prokaryotes) and only then an intensive process of biological evolution began. The possibility of the flow of abiogenesis synthesis of organic monomers in conditions modeling the atmosphere of the ancient Earth was proved in 1950s in a huge number of laboratories around the world, ranging from the S. Miller's and H. Yura's experiments. However, the path from the simple organic molecules to the simplest live cells, capable of reproduction and with heredity apparatus, is considered to be very long.

With the development of new methods of investigation the organic fossils that contained in Proterozoik and Archean rocks, and fossils of microscopic cell structures, this opinion has changed. One of the most amazing paleontological discoveries of recent decades was registration of life traces even in the most ancient rocks of the crust. Consequently, emergency of proto life on the Earth was almost an instantaneous event, evolution from organic compounds to live cells was held in very concise terms, at the very beginning of the Earth existence (Fig. 1). Nowadays has been suggested that the life on the Earth exists as much time as the planet itself. 


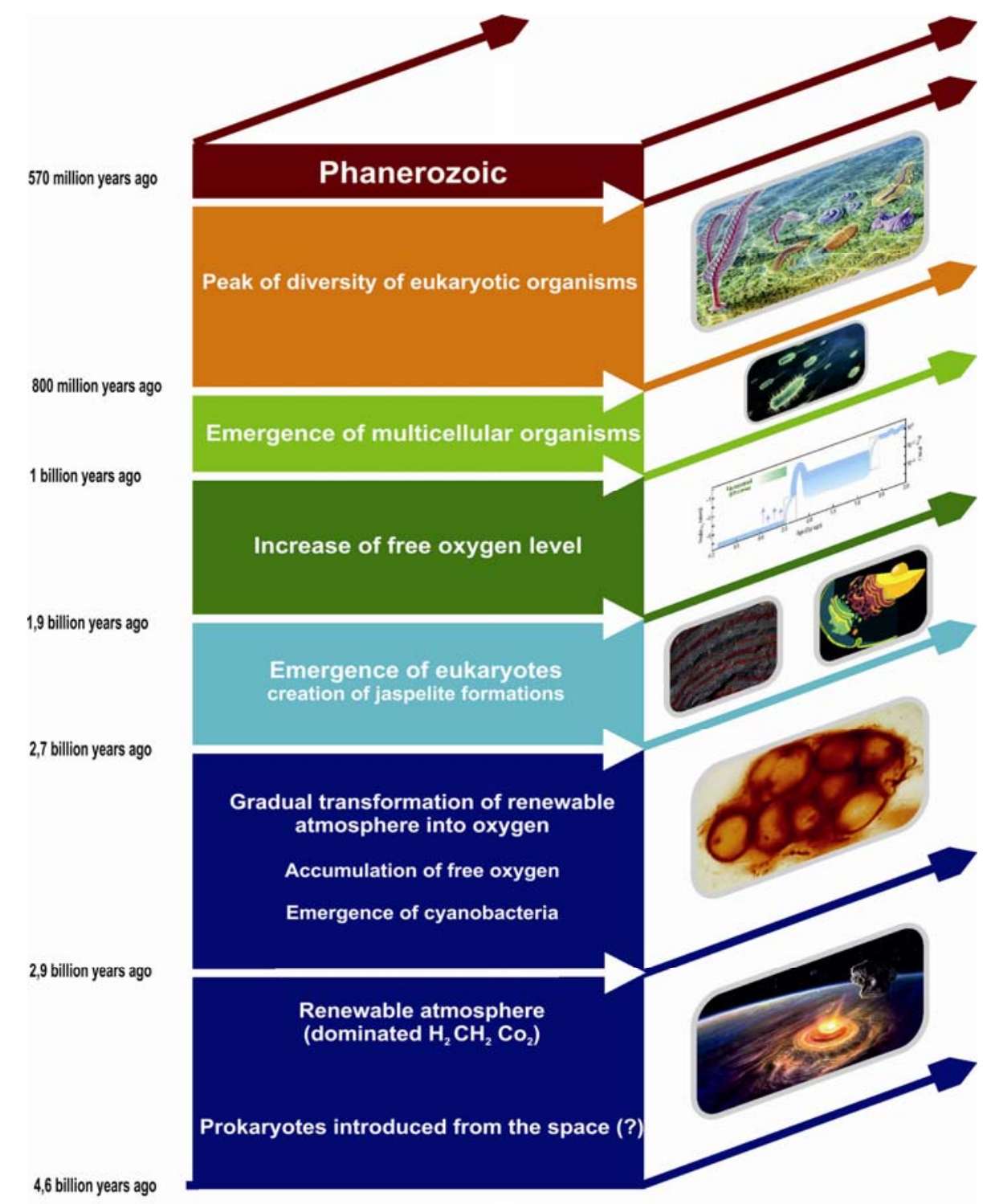

Fig. 1 The main stages of formation and development of Precambrian biosphere.

Nowadays, the theory of panspermia is one of the most debated theories of the life origin on the Earth. According to it, germs of life scattered in the space (e.g., spores of microorganisms) were transferred from the one celestial boy to another by meteorites or by the pressure of light, hence the primary living matter has a cosmic origin. This is evidenced by identifying in meteorites organic compounds of fossilized primitive organisms. Russian researchers have found in carbonaceous chondrites (meteorites) fossilized cyanobacteria and perhaps imperfect funguses; American experts-bacterial traces in debris from
Mars, and the group of scientists from Cardiff University have recently identified fossilized remains of diatoms in the wreckage of meteorite that crashed in late 2012 on the territory of Shi Lanka [2, 3] (Fig. 2).

Theories of life emergence on the Earth did not expose the issue of cell emergence. Yet there is virtually no hypothesis, which would probably describe the origin of prokaryotes. In the recent decades were developed special sedimentary rocks processing techniques that allow allocate cell membranes contained in them, and in some cases even receive indirect information about the internal structure 


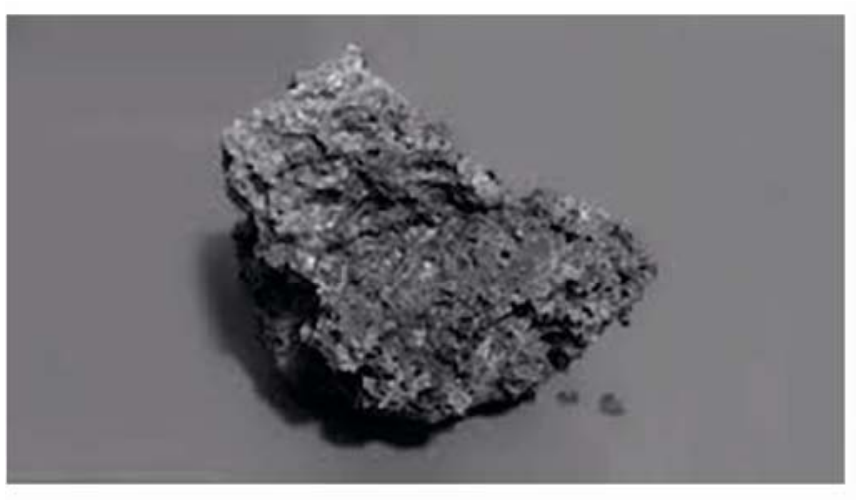

(a)

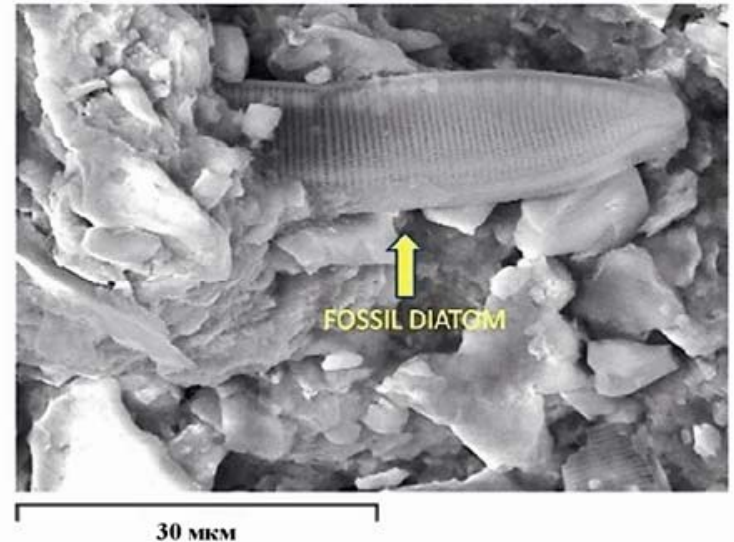

(b)

Fig. 2 Meteorite fragment was found on the Sri Lanka island (a), and identified under the microscope traces of ancient diatoms (b) [3].

of these cells. In Precambrian rocks revealed a multitude of unicellular organisms; the most ancient among them were found in Varravuna (Australia) and Onfervaht (South Africa) locations, their age respectively 3.5 and 3.4 billion years. These are several types of cyanobacteria (blue-green algae) which are almost indistinguishable from the modern. So, there was a special world in Precambrian period that was formed by prokaryotes - bacteria and cyanobacteria.

The oldest prokaryotes were likely chemoautotrophs. They adjusted themselves to any chemical reaction that occurs with releasing energy without their participation, just itself, only slow. With the help of appropriate enzyme they started to catalyze this reaction speeding it multiply. For example, the oldest prokaryotes by their anoxic photosynthesis mechanism they were restoring carbon dioxide to methane by hydrogen:

$$
\mathrm{CO}_{2}+4 \mathrm{H}_{2} \rightarrow \mathrm{CH}_{4}+2 \mathrm{H}_{2} \mathrm{O}
$$

In result of such activity in the biosphere started to form excess of methane and sulfates. There appeared symbiotic microbial groups capable to oxidize methane with the help of sulfates. In result of this again appeared carbon dioxide and hydrogen sylfide which underwent further changes. Open ended biogeochemical cycles started to close, biosphere acquired stability and capacity for self-regulation [4].

Afterwards (about 2.9 billion years ago) appeared modern look cyanobacteria that contained chlorophyll and were capable for oxygen photosynthesis:

$$
n \mathrm{CO}_{2}+n \mathrm{H}_{2} \mathrm{O} \rightarrow n\left(\mathrm{CH}_{2} \mathrm{O}\right)+n \mathrm{O}_{2}
$$

As a source of electrons they used water.

In addition, cyanobacteria (like a lot of other prokaryotes) are able to fix atmosphere nitrogen (thus a very strong connection in molecule between two nitrogen atoms breaks and appears nitrogen compounds available for use by other living organisms):

$$
\begin{gathered}
\mathrm{N}_{2}+8 e^{-}+8 \mathrm{H}^{+}+16 \text { АТФ } \rightarrow \\
2 \mathrm{NH}_{3}+\mathrm{H}_{2}+16 \text { АДФ }+16 \mathrm{P}
\end{gathered}
$$

After the emergence of cyanobacteria prokaryotes dominated on our planet for 1.5-2 billion years. Microorganisms were more numerous and more diverse.

Ancient cyanobacteria transformed early renewable atmosphere to oxygenous, linking a large number of $\mathrm{CO}_{2}$ into carbonates in the form of layered chalk-stone sediments - stromatolites with $\mathrm{O}_{2}$ release as a product of photosynthesis which slowly saturated atmosphere.

In reducing atmosphere oxygen extracted by cyanobacteria at first was spent on the oxidation of various compounds and was not accumulated in free state in the atmosphere. In this case ammonia $\mathrm{NH}_{3}$ oxidized to molecular nitrogen $\mathrm{N}_{2}$ :

$$
4 \mathrm{NH}_{3}+3 \mathrm{O}_{2} \rightarrow 2 \mathrm{~N}_{2}+6 \mathrm{H}_{2} \mathrm{O}
$$

methane and carbon oxide- to $\mathrm{CO}_{2}$ :

$$
\mathrm{CH}_{4}+2 \mathrm{O}_{2} \rightarrow \mathrm{CO}_{2}+2 \mathrm{H}_{2} \mathrm{O} ; \mathrm{CO}+1 / 2 \mathrm{O}_{2} \rightarrow \mathrm{CO}_{2}
$$


sulfur and hydrogen sulfide- - to $\mathrm{SO}_{2}$ :

$$
\mathrm{S}+\mathrm{O}_{2} \rightarrow \mathrm{SO}_{2} ; 2 \mathrm{H}_{2} \mathrm{~S}+3 \mathrm{O}_{2} \rightarrow 2 \mathrm{SO}_{2}+2 \mathrm{H}_{2} \mathrm{O}
$$

Approximately 2 billion years ago the oxygen content reached $1 \%$ of modern that is considered to be the beginning of new aerobic type atmosphere. Exactly these events enabled the development of evolution in the well-known direction.

This theory is the process of forming the modern life. Thus began a global reconstruction of biosphere which marked the development process of oxygen atmosphere.

Is such mechanism possible on the other "Earth" type planets? Undoubtedly.

For anaerobic organisms increase of oxygen concentration was a disaster because the oxygen is a very aggressive element, it quickly oxidizes and destroys organic compounds. If in anaerobic biosphere, in the stromatolites thickness left aerobic pockets where accumulated as a result of photosynthesis oxygen infused into the atmosphere, then now, when the biosphere transferred into oxygenous, anaerobic bacteria found refuge in a few anoxic pockets. In the new aerobic atmosphere could live only those prokaryotes which adapted to the high oxygen concentration in the stromatolites thickness.

Hemisphere was fighting against this poisoning oxidation of bivalent iron, which continuously flow into the ocean of magmatic effusions to trivalent, which is hardly dissolved in water and therefore escaped into sediment with carbonate in the form of siliceous-ferruginous seasonable (ocean was cold) mules. After metamorphism these mules formed characteristic for photogene rock-jaspilite. Deposits of jaspilites (ferruginous quartzite) located on the territory of Ukraine (Kryvbas).

Subsequently formed the ozone layer, which defended the surface of the Earth from falling on her deadly ultraviolet and made possible the development of more highly organized forms of life-eukaryotes. The first consequence of prereefical environmental crisis has been a massive loss of prokaryotes in the seas, the remains of which presented in the depths by Proterozoic oil, gas, graphite. This process describes the perspective of Precambrian hydrocarbon deposits.

Besides benthic prokaryote ecosystems represented by stromatolite beds, all the while existed also plankton, consisting of spherical unicellular algae — akritarh and spherical colonies. It is believed that in such ecosystems in the middle Proterozoic (about 1.9-2 billion years ago) emerged the first eukaryotes.

The peak of eukaryotic organisms' variety in the Precambrian lies in the interval of 900-800 billion years ago. Against the background of growing diversity of organisms the size was also increased [5]. Having appeared almost 2 billion years ago they did not play any significant role in the ecosystem during almost billion years, and all the diversity of these organisms was restricted by phytoplankton forms - akrytarhes.

Approximately 1 billion years ago at the end of Proterozoic era, in the evolution of eukaryotes occurred a "big bang": there were conditions appropriate for emergency of bigger and diverse organisms. Appeared multicellular organisms capable of sexual reproduction (there were found fossil embryos aged 600 million years). Previously it was believed that the development of sexual reproduction function together with genetic material exchange caused such variety. Now, however, this assumption was refuted because of genetic materials exchange. Perhaps the reason was the capability of multicellular organisms to growth, though some of their cells have already performed certain functions.

Eukaryote created an important precondition for emergence of Riphean (Late Proterozoic) multicellular plants and animals. Thus, extremely long era of domination of bacteria and blue-green algae that reached a great diversity of forms and colors in the waters of ancient ocean during the late Riphean (1,000-570 villion years ago), ended with the emergence of multicellular water eukaryotes.

With the emergence of the cell nucleus eukaryotes 
got the ability to develop complex mechanisms of modified variability. Exactly that gave them an opportunity to, first of all-to develop life cycles and sexual reproduction, secondly—multicellularity [6].

In Vendian occurred one more radical restructuring of the life on the Earth: rapid increase of partial pressure of the oxygen caused an explosion of emergency of new life forms on the Earth. Distinctive feature of all Vendian biota is lack of skeleton. Those organisms could not form a powerful mineral skeleton for two reasons: the low efficiency of enzymes responsible for biomineralization and because of the low temperatures, high solubility of carbonate (in cold water it is harder to concentrate and store).

Animals reached big sizes, some of them - up to $1 \mathrm{~m}$, but had gelatinous of feeble bodies that left prints on the soft soils. Good preservation of such prints indirectly indicates the absence of corpse eaters and big predators in the Vendiam biocenoses.

At the very beginning of Cambrian period - about 542 million years ago - the large group of animals formed mineralogical solid skeleton (Fig. 3). As in the fossil state such skeletons are usually stored and soft parts disappear completely; this event looks like a sudden emergence of various animal groups, called by scientists the Cambrian explosion (Fig. 4).

Vendian animals had not large mineralogical skeleton structures, but only dense organic conglomerates with similar functions, including spinal plates, bowls, dentiform growth, spicules and scleritis. Lack of active biomineralization (especially carbon storage) defined by conditions of cold waters, in which carbon storage is difficult (required large expenditures of energy).

Increasing amount of carbon dioxide led to decreasing $\mathrm{pH}$ of the seawater. It results the formations of mineralogical skeletons in plankton organisms complicated. High concentrations of carbon dioxide could also explain the lack of fossil calcified skeletons in Proterozoic. Low temperature during Neo Proterozoic icing also suppressed biomineralization.

In ancient organisms during the evolution formed silicon skeleton (diatoms, radiolarians). Gradually silicon was displaced by more active element-calcium. And emerged silicium-calcium skeleton, and in the most developed in evolutionary terms-calcium.

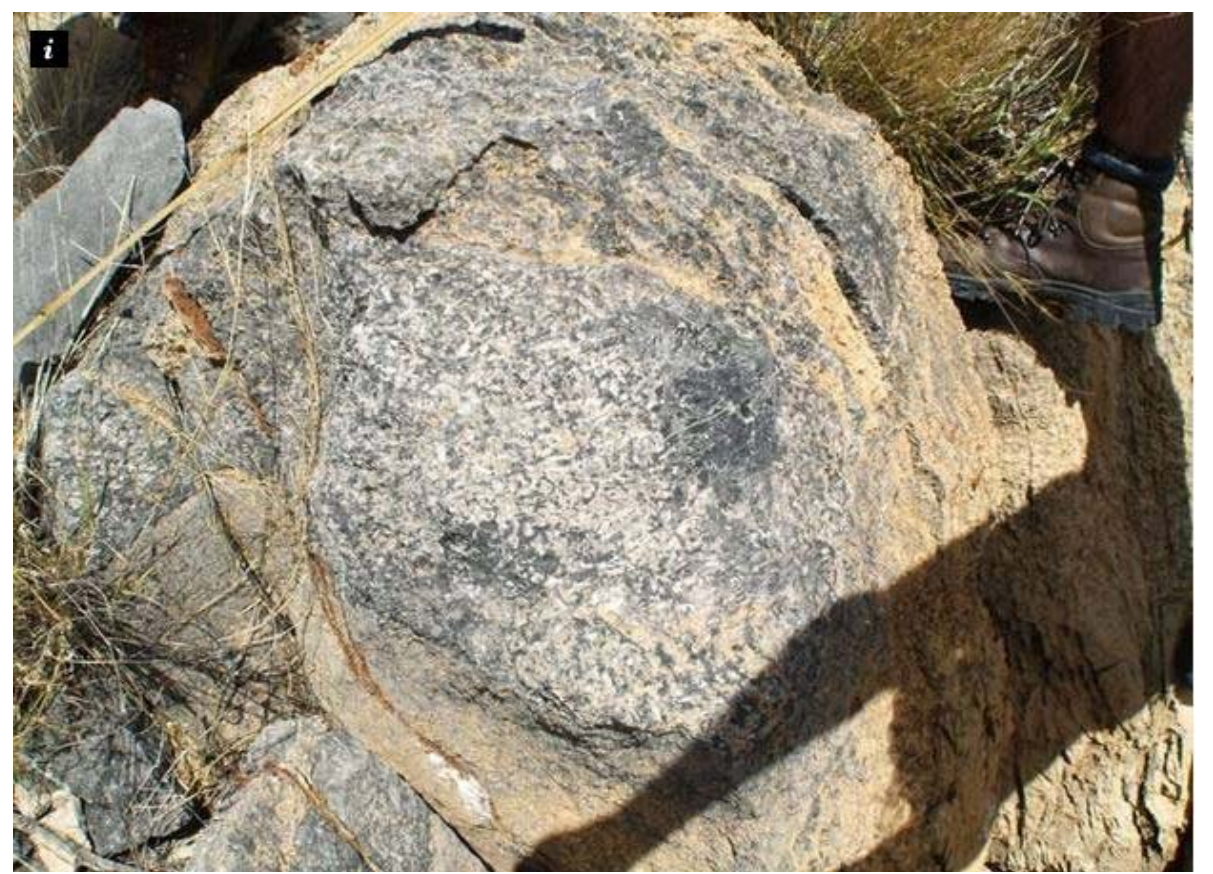

Fig. 3 Ancient coral reef formed from the remains of the first organisms with mineralogical skeleton (Namibia, South Africa) [7]. 


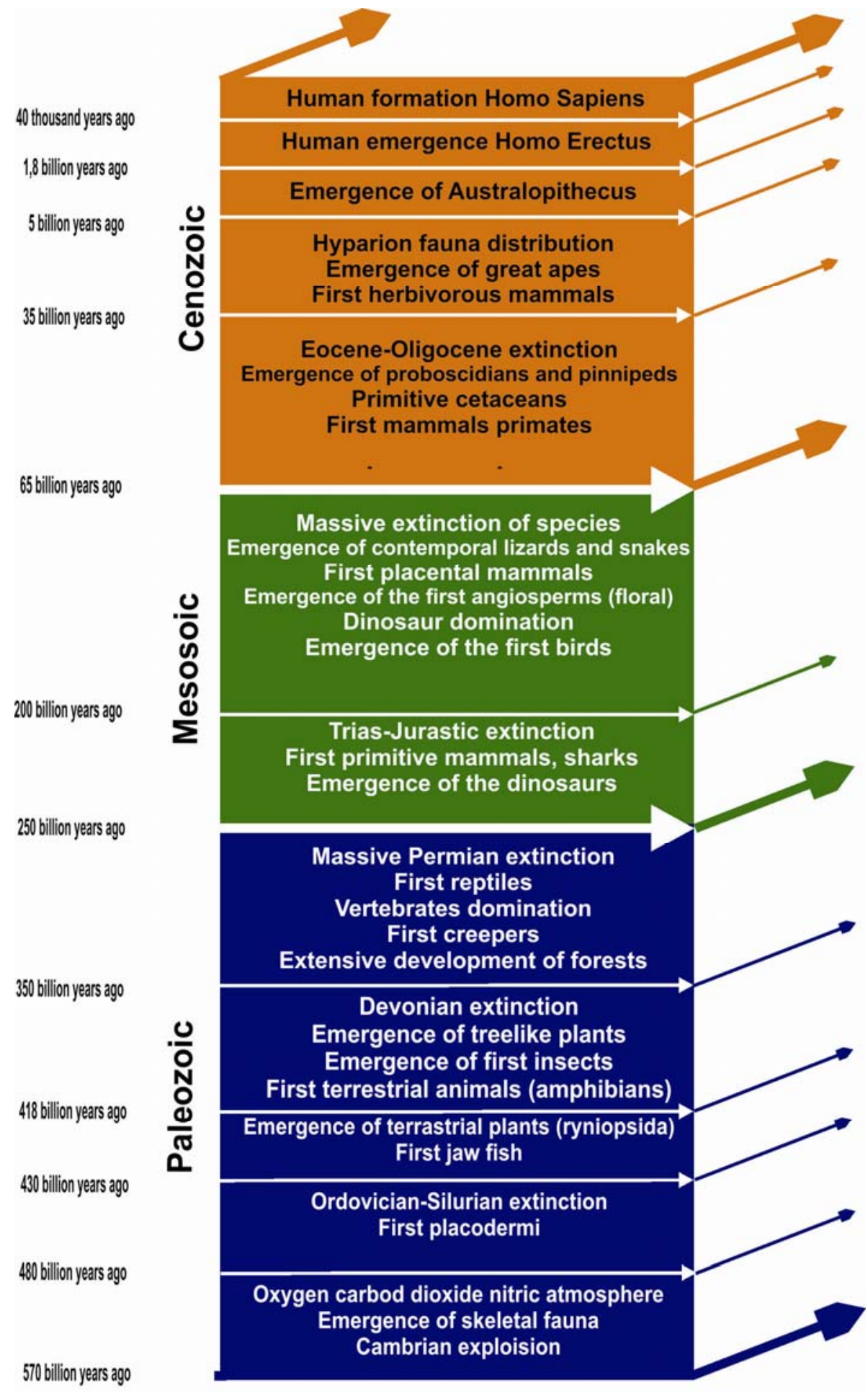

Fig. 4 Main stages of formation and development of Phanerozoic biosphere.

Later it became clear that the Cambrian ancestors of animal groups lived also before, but because they were soft bodied their remains disappeared from Precambrian rocks. Therefore the mystery of Cambrian explosion rather lies in identifying the reasons of simultaneous emergence of mineral skeleton in different types of animals. It is associated with the changes of environmental conditions, in particular-the sharp 
decreasing of the water acidity, in result of what making calcium carbonate $\left(\mathrm{CaCO}_{3}\right)$ less soluble in the seawater and easily fell into the sediment.

For the evolution of the surface of the Earth the interaction between carbon dioxide and igneous rocks is very important. Thus silicates decomposed by washing out alkaline (Na) and alkaline earth $(\mathrm{Ca})$ metals. In the first case the water was fed by $\mathrm{NaHCO}_{3}$, in the second $-\mathrm{Ca}\left(\mathrm{HCO}_{3}\right)_{2}$.

In geological time scale carbon acid leaching in considered to be crucial for the removal of carbon dioxide from the atmosphere [8]. In the reverse reaction

$$
\mathrm{Ca}\left(\mathrm{HCO}_{3}\right)_{2} \rightleftharpoons \mathrm{CaCO}_{3}+\mathrm{CO}_{2}+\mathrm{H}_{2} \mathrm{O}
$$

half of the carbon dioxide returned to the cycle and the rest deduced from it with the formation of carbonates.

During the Archean-Proterozoic chemical weathering contributed to the formation of powerful carbonate platforms in the contact zone of continents and oceans as one of the main sedimentary rocks. This process involved cyanobacteria groups that formed stromatolites thickness. In Phanerozoic they were substituted by eukaryotes with carbonate skeleton which formed reefs.

The reaction of carbonate-hydrocarbonate equilibrium

$$
\mathrm{CO}_{2}+\mathrm{H}_{2} \mathrm{O} \rightleftharpoons \mathrm{HCO}_{3}{ }^{-}+\mathrm{H}^{+} \rightleftharpoons \mathrm{CO}_{3}{ }^{2-}+2 \mathrm{H}^{+}
$$

implies that $\mathrm{pH}$ of the environment depends on available $\mathrm{Ca}^{2+}$ : until it is not spent, exceeding carbon dioxide enters the carbonates and $\mathrm{pH}$ does not increase. At the same time until there is $\mathrm{CaCO}_{3}-\mathrm{pH}$ is not decreasing because carbonates dissolve. Composition of the solution depended on the ratio $\mathrm{Ca}$ and $\mathrm{Na}$ in the igneous rocks. Especially reinforced leaching of crushed volcanic products by the groundwater, that was often combined with the high temperatures of the Riftogene areas.

However, under normal conditions dioxide leaching is rather slow process, accelerated by biota influence in 10-100 times. So, in the neutral environment the development of living organisms is associated with the presence of calcium in it.
Simultaneous massive emergence of skeletons (carbonate, phosphate and silicium) in multicellular animals at the beginning of Cambrian could be explained by warming or by animals' colonization of low latitudes.

The other factor could be and increasing biologic diversity and connected with it trophic chain elongation. Concentration of ions (especially calcium, magnesium, phosphorus, and silicium) has grown exponentially by the trophic chain. There was a need for its withdrawal of detoxification. In some invertebrates appeared an opportunity to build the mineral skeleton due to detoxification in terms of warm-water habitats where solubility of the most biominerals is lower and the efficiency of respectable for mineralization ferments is higher than in cold waters. Perhaps animals could not colonize warm-water places until sufficiently increased the level of oxygen. In warm water oxygen dissolves less. It is known that eukaryotes carry overheating worse than prokaryotes and the simplest that may be connected with its increased need for oxygen.

But for the formation of carbonate skeletons of animals it was not enough only to be in favorable environmental conditions. They needed special genes and enzymes through which animals could control creation and growth of carbonate calcium crystals in the right place and in the right quantity.

The most important role in creation of carbonate skeletons plays an enzyme of carbonic anhydrase [9], which approximately in a million times accelerates the conversion reaction of dissolved carbon dioxide to hydrocarbonate:

$\mathrm{CO}_{2}+\mathrm{H}_{2} \mathrm{O}^{-} \rightarrow$ Carbonic anhydrase $\mathrm{HCO}_{3}^{-}+\mathrm{H}^{+}$

Carbonic anhydrase is much widespread in the living world, including prokaryotes. Besides biomineralization it takes part in many other functions (regulation of $\mathrm{pH}$, ion transportation, removing $\mathrm{CO}_{2}$ from the textures etc.).

In result of formation of animals skeleton in the Cambrian emerged new ways of being within the 
marine shallows. Sponges received an ability to filter bacteria, trilobites - to bury into the bottom sediments, mollusks - to crawl across the surface of the seabed. Brahiopods, Pearlworts and Echinoderms were able to rise vertically out of water, to hold over the surface and to filter the water more efficiently in order to obtain food. Without solid parts of body such way of living would be impossible or at least less productive. According to the American scientist D. Hutchinson the emergence of skeletons in the living organisms at the beginning of Phanerozoic, which are capable of fossilization, reflects mainly the occurrence of predation. Until then the biosphere was a generally peaceful kingdom in which there was no need for protective shells.

During the Cambrian period there were huge areas on the Earth occupied by continental shelf or by shallow. Here were created ideal conditions for life: bottom covered with soft mud and warm water. By that time the atmosphere contained much oxygen, though it was less than today.

During the Phanerozoic organisms have undergone considerable restructuring (biotic processes) which were recorded by the variety changes of organisms. There was mass emergence of new groups of organisms of the high taxonomic rank and dying of the old organisms.

For the long time global catastrophes which could influence the evolution of the Earth living remained without interest. It was more important for geologists and paleontologists to understand the progressive and continuous changes of species. Only recently, in the middle of the last century, when it was found that global extinctions coincide in time with catastrophic events such as volcanic outbursts and meteorites falling, they have begun to study purposefully.

It was first time mentioned about disasters that occurred on the Earth in the past, at the beginning of XIX century by the French naturalist Georges Cuvier. The scientist pointed out that the land horizons rich in prehistoric animals' remains alternate with the land horizons poor in such findings. Thus G. Cuvier discovered that in every new layer rich in bones the remains belong to animals of other species but not to those who were found in previous and following layers, i.e., not to those who lived on the Earth earlier or later according to the geological time scale.

Oxygen disaster is one of the most important events in the Earth's history, just because of it in the atmosphere of our planet appeared oxygen, without which we could not live. This important environmental event occurred about 2.5 billion years ago.

Formation of oxygen atmosphere is a crucial event that explains biosphere mechanisms of transformation from prokaryotes that were breathing nitrogen, methane etc., and extracted oxygen to the higher, more organized forms of life that used oxygen for the life support.

Progress in the further development of life largely depends on the geological processes that adjusted the way of biota development. Should not be refused the progressive movement of improving the living conditions of organisms' self organization.

So prokaryotes, which led to the formation of oxygen atmosphere, brought them to death, creating a qualitatively new platform for life-eukaryotes development, whose life energy was based on the process of breathing.

Cambrian explosion-sudden occurrence (in the geological sense) in the Early Cambrian fossil sediments (about 540 million years ago) of representatives of various divisions of the animal kingdom on the background of fossils' absence or their ancestors' fossils in Precambrian sediments.

Ordovician-Silurian extinction-is a massive extinction at the border of Ordovician and Silurian periods - about 450-440 million years ago: the third of the five biggest extinctions in the Earth's history by the number of extinct and the second - by the loss of living organisms.

Nowadays Ordovician-Silurian extinction studies intensively. Timeline corresponds to the beginning and 
ending of the hardest Phanerozoic ice ages which marked in the end by the long cold snap in the Upper Ordovician. This adversely affected the fauna of the Late Ordovician for which the greenhouse climate was typical. This was preceded by the reduction of atmospheric carbon dioxide that selectively affected organisms from the sea shallow. Glaciers held water; in the interglacial period-release it; because of it the level of the great ocean fluctuated several times. The level of large shallow intracontinental seas of the Ordovician increased, collapsed ecological niches, and then it came back to the previous state, decreasing the population; often entire families disappeared. Died more than $60 \%$ of marine invertebrates, including two-thirds of all brachiopods and pearlworts families. Information about icing was found in the sediments of Sahara Desert.

Nowadays a lot of scientists adhere to the theory that the reason for the beginning of extinction was a flash of gamma-radiation from the super nova which is 6 thousand light years far from the Earth (according to the Earth in the close arm of the Milky Way galaxy). Ten second outburst led to the thinning of the Earth's atmosphere by approximately twice, exposing the organisms living on the surface including respectful for planetary photosynthesis to the strong ultraviolet radiation. However, unambiguous evidences of such gamma flares occurrence were not found.

Devonian extinction - massive extinction of species at the end of Devonian, one of the biggest extinction of flora and fauna in the Earth's history. The First (the strongest) peak of extinction confined to the Early Famennian stage - the last stage of Devonian period, about 374 million years ago, when suddenly disappeared almost all agnathans. The Second impulse completed the Devonian period (about 359 million years ago). Totally died out $19 \%$ of families and $50 \%$ of genera. The reasons are still unclear. Basic theory suggests that the main reason for extinction in the oceans were changes of the water level and decreasing of the oxygen level in the great ocean. Probably the activator of these events was global cooling or extensive ocean volcanism, though the falling of extraterrestrial body such as comet is also quite possible. Some statistical studies of marine fauna of that time suggest that reducing the diversity of living organisms was likely connected with the decline in the rate of speciation than with growth in the rate of extinction.

Massive Permian extinction or Permian-Triassic (P-Tr) extinction (colloquially known as the "Great Dying" or the "Great Permian Extinction"- one of the five mass extinctions became a boundary which divides Permian and Triassic periods, i.e., Paleozoic and Mesozoic, about 251.4 million years ago. It is the Earth's most severe known extinction event, with up to $96 \%$ of all marine species and $70 \%$ of terrestrial vertebrate species becoming extinct. It is the only known mass extinction of insects. Some $57 \%$ of all families and $83 \%$ of all genera became extinct. Because so much biodiversity was lost, the recovery of life on Earth took significantly longer than after any other extinction event. Models according to which it occurred are under consideration.

Nowadays scientists have no consensus on the reasons of extinction. Considering several possible causes such as gradual environmental changes (anoxia - changes in chemical composition of the sea water and the atmosphere, in particular oxygen deficiency; increased dryness of the climate; change of ocean streams and (or) the sea level under the influence of the climate changes) and catastrophic events (falling of one or more meteorites, collision of the Earth with the asteroid with a several $\mathrm{km}$ diameter; strengthening volcanic activity; sudden release of methane from the seabed).

The most common is the hypothesis according to which the cause of the disaster was outpouring traps (first of all relatively small Emeishan about 260 million years ago and then huge Siberian traps about 251 million years ago). This could be related to volcanic winter, greenhouse effect due to release of volcanic 
gases and other climate changes that affected the biosphere.

Trias-Jurassic extinction, which is the boundary between Triassic and Jurassic periods (200 million years ago) - one of the biggest extinctions of Mesozoic era, which significantly changed the life on the Earth. The whole class of conodonts which accounted for $20 \%$ of all marine families, all widely spread non-dinosaurian archosaurs, a lot of amphibious species fully disappeared. Least half of the currently known species that lived on the Earth at that period died. Due to that event released ecological niches and began to dominate dinosaurs from Jurassic period. This event happened in less than 10,000 years and occurred just before Pangaea started to break apart. Several explanations for this event have been suggested, but all have unanswered challenges:

- Gradual climate change, sea-level fluctuations or a pulse of oceanic acidification during the late Triassic reached a tipping point. However, this does not explain the suddenness of the extinctions in the marine realm.

- Asteroid impact, but so far no impact crater of sufficient size has been dated to coincide with the Triassic-Jurassic boundary.

- Massive volcanic eruptions, specifically the flood basalts of the Central Atlantic Magmatic Province (CAMP), would release carbon dioxide or sulfur dioxide and aerosols, which would cause either intense global warming (from the former) or cooling (from the latter).

- Methanehydrate gun hypothesis: warming in result of volcanism and accumulation of carbon dioxide in the atmosphere led to release of methane from the bottom clathrates; release of methane- $\mathrm{a}$ stronger greenhouse gas than $\mathrm{CO} 2$ - accelerated the warming even more that relatively intensified the process of methane release from the ocean bottom and caused rapid changes of global temperature.

The Cretaceous-Paleogene extinction (about 65 million years ago) is characterized by the new massive extinction: disappeared approximately $40 \%$ of all animal families of that time. Disappeared pterosaurs, ammonites, mosasaurs, but the main victims of this disaster were dinosaurs of course. The reasons of this extinction remain unclear.

There are two substantially opposite hypotheses. According to one of them more highly organized groups destroyed less organized. An important role belonged to the paleogeographic changes such as rapid increase of land area. At the center of second hypothesis lie catastrophic processes, in particular meteorite falling. It could cause sharp changes of air and water temperature, changes of atmosphere composition and the level of solar radiation etc. It should be mentioned that both hypotheses have their right to exist and the search of scientifically based evidences remains actual.

Eocene-Oligocene extinction (according to the European fauna it is also known as the Great Break (French "Grande Coupure")) — caused significant changes in marine and terrestrial flora and fauna. Began in the late Eocene-early Oligocene about 33.9 \pm 0.1 million years ago. Considerably inferior in the scale to five biggest extinctions is in the Earth's history. In oceans this extinction was much extended in time and lasted for about 4 million years (the end-late Eocene). The total extinction of marine animals was estimated at 3.2\% which is several times higher than the background indicator $0.66 \%$. More than half of extinct families in the late Eocene were foraminifers and sea urchins. At the genera level significantly died (about 15\%) sea benthos. According to the certain types we could distinguish the extinction of ancient cetaceous in this period.

There are several hypotheses that explain reasons of extinction paleontologists have no consensus about them. Reasonable and sufficiently studied theories are:

- Earth collision with asteroids - according to many scientists rapid climate changes that led to the extinction were caused by two consecutive meteorite crushes which felt in the North America-Chesapeak Bay and in Siberia-Popigai; due to the sharp decrease 
of the temperature significantly changed the concentration of carbon dioxide; a lot of meteorologists associate the process of Antarctic ice shield formation with Oligocene; although it should be mentioned that the influence of asteroids falling on climate in geological scale is rather brief;

- Supervolcanic eruption-some scientists claim that 23 of 47 known supervolcanic eruptions occurred in this period of extinction; huge territories of the present-day North America were covered by kilometer sediments layers of tuff and ash; the term supervolcanic eruption means the special kind of eruptions that originated from the system of radial cracks where magma accumulation raises the whole volcanic region but not the only volcano; relatively the volume of emissions into the atmosphere in times exceeds the volume of emissions of conventional volcanoes;

- Climate change at the boundary of Eocene and Oligocene;

- Partial eclipse of the Earth by its hypothetical rings - In 1980s there was a theory of possibility of the rings system existence in a certain period of Earth's development, similar to the rings of Jupiter. Their further exploration prompted some scholars to believe that its shadow could cause global climate cooling, which relatively caused the extinction of many species of marine organisms in the late Eocene.

Formation of conscious being of living organisms is associated with the emergence of the genus Homo and society, which coincides in the time scale with the Neogene and Quaternary stratigraphical scale (Fig. 5). In the temporal periodization this boundary was considered from the same positions as the origin of life. If the life in terms of information is the emergence of genetic code, so called species memory, the human society is the emergence of cultural information that is the code language of abstract symbols and memory transmission during study.

One of the human ancestors is considered to be fossil creature-Pithecanthropus (from Greek $\pi i \theta \eta \kappa о \varsigma-m o n k e y$ and äv $\theta \rho \omega \pi \circ \varsigma$ - human)
- subspecies of human as an intermediate link between Australopithecus and Neanderthals who lived about 700-27 thousand years ago. Nowadays Pithecanthropus is considered to be a local variant of Homo erectus, which combines the features of monkey and human. Having appeared on the Earth these creatures had to learn how to make tools and use them in order to obtain food, make clothes, and build houses. This all gradually formed their substantive consciousness aimed at the transformation of natural objects on items needed to meet their needs.

Further development of human consciousness occurred under the influence of other strong factor-speech. The emergence of language in the life of primitive man is a natural process because labor activity from the very beginning had a social character. Manufacturing of working tools and their application required the joint activity; and the exchange of working tools and products contributed the intensive communication. The need of communication led to the emergence of speech with the help of which people shared their knowledge and experience. Due to joint activity and language communication instinctive relationship in tribes started to be replaced by consciousness, and tribes were replaced by society.

Process of human formation ended only in the Upper Paleolithic period (about 40 thousand years ago) when the present human type-Homo sapiens—wise person (Cro-Magnon).

In general, it is hard to draw the line which separates the human and the animal, as the boundary between living beings and non-living. Therefore the information criteria-emergence of speech and genetic code is the clearest. But this process is inseparable from social relations. Otherwise speaking, the human emerged not alone, but in the form of society just like the life emerged not in the form of organism, but in the form of living matter or living matter fields [10].

According to the recent data based on the concept of Y. L. Semenov [11], the human emergence geologically was an instantaneous event and was 


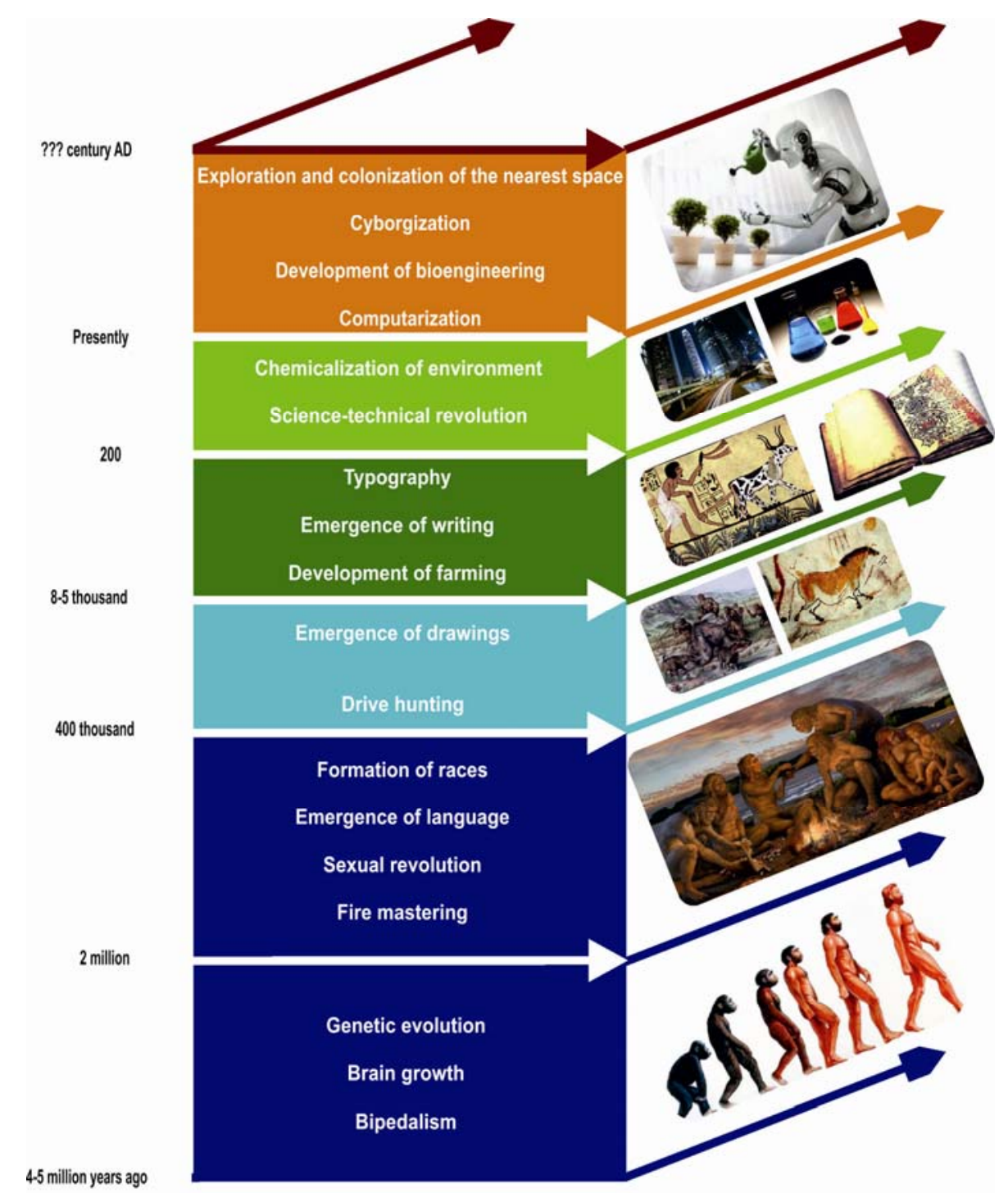

Fig. 5 The main stages of formation and human development.

Connected with the sexual revolution. It is known that in animal world estrus - period of female sexual excitability is strictly limited (monkeys have about 5 days) and only women - permanent. Short duration of estrus of Australopithecus caused the reduction of their tribes because they could survive only in conditions of a rigid biological dominating system of the strongest male. Therefore in the process of evolution created favorable conditions for the rapid brain growth (100-30 thousand years ago) and the extension of estrus in result of such mutation. In tribes relations between males became more patient and hunters and meat-more. As a result, system of biological domination during one-two generations in this population could be replaced by the system of social relations. So, the biological shift from female to woman (Eva) was a huge progress in evolution-access to the new informational and energetic levels as it signified speech formation, transition to the fire capturing.

Approximately in the second millennium BC emerged writing - a powerful tool of fixation and retranslation of socio-cultural achievements; approached the era of civilization; occurred the social division of labor, aroused cities, developed barter, laid the foundation of legal regulations of relations between 
people, aroused countries and the first written laws.

Eventually human with appropriate production means became the main geological force and consumer of energy resources of the planet. The development of patriarchal society, having chosen the nature subjugated ideology, provided its own rapid progress through the increase of expansion into the nature and degradation of the last. Logically it led to the second global ecological crisis (the first-oxygen disaster), in result of which the biosphere began to be displaced by the technosphere, which forms the third neo-cybernetic life shaft, adapted to any non-oxygen environment, including the space.

Problems facing the humanity are closely related. Rapid increase of population leads to more intensive use of natural resources, aggravating the food problem.

Even today humanity consumes natural resources in much larger amounts than it could be extracted from the biosphere without causing damage to its biochemical cycles and without disruption of self-recovery. Otherwise sayings, the humanity from the XX century live at the expense of their descendents. Moreover it has put the biosphere, and consequently itself as an integral part of the biosphere, on the edge of complete degradation.

Due to the sharp aggravation of environmental crisis and realization of the fact, that it is impossible to have healthy society and economy in conditions of worsening the quality of environment, a lot of scientists and organizations in 1970s began the research of real ways of the Earth's development by the preservation of current tendencies or ecologic adjustment of further development. Have been offered "scenarios" of the Earth's development, which were more frequently based on a personal authors' personal concepts of possible development, and rarely-on scientific prediction of existing trends consequences (uncontrolled population growth, intensification of economy without considering the physical capabilities of the Earth etc) using powerful computer models. By the present day there were developed various scenarios, which significantly differ by the degree of scientific validity and objectivity. Some of them are of frankly emotional apocalyptic character and warn about the imminent disaster; others are more objective and give concrete recommendations for action [12-14]. Let us consider the main scenarios of humanity development in the Technogene.

Environmental voluntarism (Lat. voluntas-will), based on anthropocentric principles of the purpose of nature to meet not just the humanity needs but also the needs of every individual, misconceptions about the inexhaustibility of natural resources and limitless possibilities of the human. In predicted period of time it will lead to the emergence of phenomena called "environmental boomerang"-negative impact of environmental factors on all spheres of human existence. Environmental voluntarism entails the desire of extensification of existing methods of management, negation of the need of its intensification on the new scientific and technical basis. It is characterized by the absence of ecological thinking, complete ignoring environmental laws, misunderstanding of inevitability of transition to new technologies that under increasing the socio-economic effect would be simultaneously ecologically rational, and then of transition to development within economic capaciousness of ecologic system. The scenario itself is historically interesting but concrete economic activity is often based exactly on intuitive perceptions of immediate benefit from these or other projects [15].

Scenario of nature management is based on the necessity of the biosphere preservation as a foundation of human being. Required the use of natural resources taking into account "ecological imperatives"-restrictions aimed at preserving resource's potential of the planet through "ecologization of production" and promoting recovery processes based on learning and observation of the Nature's laws.

Technocratic scenario is based on the recognition of possibility of complete replacement of the biosphere as 
a source of human required resources by the technical tools. Also admits the replacement of human by the "artificial intelligence" and "cyborgs"-biocybernetic organisms with a human mind and mechanic body; the human's role is reduced to the production of the necessary cyborg parts.

The Space scenario foresees the use of space for the resettlement of humanity, obtaining resources, waste disposal and resolving issues that could face people. Sooner or later humanity will have to leave the Earth and to begin colonization of other stellar systems. On this depends not only its survival - for humanity as a kind development forwardly is rather peculiar. Coming out of the geographic boundaries and biological limits it caused further development of civilization that led to technologic, social, politic and economic spheres of life.

Back to the nature-scenario, based on the view widespread among ecological extremists, who believe that despite the irreversibility of historical development humanity can return to the pastoral idyll of the past and satisfy their needs only with the help of harvesting. Humanity do not have to make a step forward (as suggested by most futurists) but they have to make a giant leap backwards. The main precondition is that society now is generally a consumer, so must take course on conscious regression (from the evolutionary point of view) to the state when human do not cause damage to the planet, nature and itself. The ultimate goal will be the end of civilization and return to the jungles.

Ahead to the nature - creation of organisms with the help of genetic engineering with new properties that being involved into ecosystems will control them in a given direction. Future where nature will become much more exuberant and lush than we could imagine. New trends of environmentalism and transhumanism (such as technogaianism) determining the development of technologies aimed at recovering the environment. Nano- and Bio-technologies could be used for cleaning dumps and destroying wastes. And in the far future it could transform the Earth to its original form.

The founder of cyberpunk American science fiction writer Bruce Sterling spoke Oct. 14, 1998 in San Francisco with a report that claimed that in order to deal with environmental problems humanity have to use the most advanced technologies and work together.

In the far future our planet could become ecologically more diversified than it has ever been in its history. People should be genetically modified so they do not interfere with total harmony of the environment. All the energy needs of humanity will be satisfied once and forever-we will become a civilization of the first type by the scale of Kardashov (planet civilization uses its resources completely; planets of its stellar system colonize and become a part of the resource base). Some environmentalists also advocate for adjustment of the Earth's ecosystem: destruction of predators, so that herbivores would not suffer. It will be possible to control the weather and facilities of defense from natural disasters - asteroids, earthquakes, volcanic eruptions.

However, an intervention of the newest biotechnologies is still unpredictable, especially more changing ecosystems in their implementation.

Catastrophic scenario admits the destruction of humanity in result of one of the human-kind disasters: nuclear war, resource depletion, pollution and so on.

As the result of a possible nuclear war permeability of the atmosphere for the sunlight will be decreased due to the pollination; in result of the global climate change will start the "nuclear winter" that will lead to the chain of negative reactions in the biosphere until its complete collapse.

Environmental disaster as a result of economic activity will be a logical final of progress of civilization, replacement of nature for technosphere-system which self-developing, to control which no one can because of its complexity.

Degradation of humanity - is degeneration of human due to the change of hereditary apparatus in result of mutagen effect of polluted environment, 
spiritual and moral degradation (targeting material consumption, drug addiction, and alcoholism). A lot of people cause harm to their health, perfectly realizing the negative consequences (e.g. smoking, drinking alcohol, drugs, and other psychotropic medications) and the same time government actions of some countries clearly indicate their specific interest in developing such business. In the future humanity may face the problem of global using of medicines containing drugs or drugs themselves; and advertisement efforts seem to be intended to teach children that medications are something vitally necessary and common. Medications convert from the mean of treatment to food, and this threatens the extremely serious consequences in the future of humanity.

In the UN documents adopted in the 1992 in Rio de Janeiro as a new theory of humanity and environmental existence was proposed the concept of sustainable development. It was formulated as a way of overcoming the main environmental threat of the modern civilization, which existed in the form of some theoretically grounded danger being considered by relatively narrow circle of scientists and politicians and connected with overpopulation, irreversible expenditure of non-renewable mineral resources, and with environmental pollution. Sustainable development predicted the harmonization of humanity relations with the biosphere, its development in harmony with the laws of nature, that become possible only under the condition of conscious restrictions on resource consumption, based on the capacity of biosphere. The main goal of sustainable development is improving the quality of human life without disturbing the stability of ecosystems. Although in general the concept of sustainable development was adopted by the international community, until nowadays it is not clear how to reach this goal and evaluate the degree of approximation to this goal, because the definition of primary needs differ a lot for people from different countries and continents.
In June 2012 held the United Nations' conference on sustainable development "Rio +20 " that showed that today, unfortunately, the international community is not ready to seriously, at the political level, approach to the issue of the global future. Economic way of thinking is dominating and it is not concerned with the long term consequences.

There is a significant difference occurs in the modern world between existing in some countries mineral resources and consumption volume in different countries. Nowadays, there is a well known fact that $20 \%$ of population on the Earth living in industrialized countries consumes $80 \%$ of all resources, while the rest $80 \%$ living in underdeveloped countries - only $20 \%$.

Nowadays there is a fierce competitive struggle for the main resources of the planet Earth between the leading countries of the world. The world becomes the area of struggle for geopolitical interests; inequality is considerably growing; increasing the popularization of society.

According to this scenario the world could be divided into protectionist blocks, countries will conduct a brutal war for vital resources, such as water and energy — oil and gas.

Developed countries, preserving a high level of consumption for their population, by politic, military, and economic measures will keep the rest of the world in undeveloped industrial state as a raw appendage, areas for dumping hazardous wastes and the source of cheap labor.

Under conditions of such struggle between transnational corporations for the influence on different continents in order to prevent destruction of the biosphere by using nuclear weapon the only solution is modernization of international relations system: transition from the open confrontation to the partnership and beneficial coexistence.

One more important perspective of society development is human informatization-highly organized socio-economic and scientific-technical process of creation and development of favorable 
conditions to meet the information needs using informational resources. One of perspective scientific directions is global modeling or creation of mathematical models that are implemented on supercomputers with the help of which various solutions of global problems are evaluated.

As the characteristic human feature is excessive consumption the scientists suggest in the future to correct this damaging feature by changing human mind on artificial intellect, otherwise saying, to conduct cyborgization of society. Scientists will learn not only to recreate every part of human body but also to adjust needs and possibilities of human in different environmental conditions that will ensure the existence of living organisms even in extreme conditions.

But such scenario of future development could take a different direction if machines with inhuman intellect would start improving and human would be unable to stop this process. It will lead to extremely rapid technological development, to creation of the world where technologies will surpass human and will manage financial markets, scientific researches, people and weapon development that is not available for our understanding. Therefore it is difficult to predict the consequences of artificial intellect creation.

On the one hand, most of scenarios of the Earth's development are rather pessimistic, critical state of the planet is expected in the middle XXI century, on the other hand - there are a number of undoubted achievements of humanity, which leave a hope for overcoming the main crisis events and gradual achievement of sustainable (environmental) state of planet and all countries.

\section{Conclusions}

Humanity has set the biosphere and consequently themselves as an integral part of the biosphere on the edge of complete degradation. Rapid growth of population on the Earth and rapid increase of use of natural resources put new challenges to humanity which consist of the space exploration, the search of life on the neighborhood planets and their exploitation in the future. The way of evolution which passed the Earth from the early formation, the long process of emergence and development of life, insufficient knowledge of the universe give a reason to believe that analogous physic-chemical processes could occur on the other planets. Questions arise: "Is extraterrestrial life in the universe possible? Could be repeated the way of evolution that passed Earth on the other planets?" Biosphere crisis arises the question of necessity of using scientific and technical potential of humanity to find a solution of this situation.

Based on the knowledge possessed by humanity today, one of the variants of solution is searching planets available for human developing. In the basis of our forecast lies the model of life formation from eukaryotes to human, otherwise saying, from simple to complex during more than 3.8 billion years.

\section{References}

[1] Eskov, K. 2004. "History of the Earth and Life on it: from Chaos to Human." M.: NTS ENAS, 312.

[2] Rozanov, A. Yu. 1996. "The History of the Skeletal Faunas Formation." Soros Educational Magazine 12: $62-8$.

[3] Wickramasinghe, N. C., Wallis, J., Wallis, D. H. et al. 2013. "Fossil Diatoms in a New Carbonaceous Meteorite." J. of Cosmology 21 (37): 9560-71.

[4] Zakharov, V. B., Mamontov, S. G., Sonin, N.I. et al. 2007. Biology. Grade 11. Profile Level. M.: Drofa Publisher, 283.

[5] Rozanov, A. Yu., and Fedonkin, M. A. 1994. "The Problem of the Primary Biotope of Eukaryotes." Ecosystem Restructuring and Biosphere Evolution. M.: Nedra, 25-32.

[6] Markov, A. V. 2005. "The Origin of Eukaryotes." Paleontologist. Magazine. 2: 3-12.

[7] Penny, A. M., Wood R., Curtis, A. et al. 2014. "Ediacaran Metazoan Reefs from the Nama Group, Namibia." Science 344 (6191): 1504-6. Doi:10.1126/ science.1253393.

[8] Zavarzin, G. A., and Zhilina, T. N. 2000. "Natron Lakes-A Natural Model of the Ancient Continental Biosphere." Nature. 2: 45-55.

[9] Kupriyanova, E. V., and Pronina, N. A. 2011. "Carbonic Anhydrase-An Enzyme that Converts the Biosphere." Plants Physiology 58 (2): 163-76.

[10] Rudko, G. I., and Adamenko, O. M. 2009. Earthology. 
Ecological and Resource Safety of the Earth. K.: Akadempres, 512.

[11] Semenov, Yu. 1987. "Origin of Human in the Light of Current Scientific Data." Vestn. USSR Academy of Sciences 7: 120-30.

[12] Reimers, N. F. 1992. Hopes for the Survival of Humanity. Conceptual Ecology. M.: Rossiya Molodaya, 367.

[13] Stepin, V. S. 1990. The Epoch of Changes and Future Scenarios. 1996: The Abridged Version of Author's Article "Philosophical Thought at the Turn of Two
Centuries", published in digest "Philosophy in the contemporary world". Philosophy and life. Scientific-pop. ser. N 11.

[14] Tetior, A. N. 1999. Sustainable Development of the City. M.: Committee on Telecommunications and Mass Media of the Government of Moscow, 173.

[15] Krasnoshchekov, G. P., and Rosenberg, G. S. 2002. Ecology "in Law" (Theoretical Constructions the Modern Ecology in Quotations and Aphorisms). Tolyatti: IEVB RAN, 248. 